\title{
The challenges of launching a MOOC and reusing that material in a blended campus class
}

\author{
Kevin G. Dunn, kevin.dunn@mcmaster.ca \\ Department of Chemical Engineering, McMaster University, Hamilton, Canada
}

\begin{abstract}
Online courses are launching daily on the various massive open online course (MOOC) platforms, such as Coursera and edX. These electronic resources are costly to develop and often likened to sunk "capital costs", as contrasted to ongoing "operating costs" of a traditional face-to-face class. To complete this economic analogy, it makes sense to amortize, or profitably reuse those electronic materials in the university classroom, as a way to achieve a blended class. It is also worthwhile learning from others' experiences so those large capital and labour-intensive investments of video and resource development are used profitably.
\end{abstract}

There are some shortcomings and counterintuitive aspects to the fully online class, described in the paper. The experience of the author using these MOOC materials in his active-learning flipped class is described. Plentiful advice is available online regarding the blended class, and we give feedback and commentary on the various successes and failures experienced when running this advanced, final-year engineering statistics course. What activities to use during scheduled class-time is one of the more daunting questions for the instructor flipping a course, so this section is covered in greatest depth. Some student qualitative feedback is interspersed throughout.

Keywords: MOOC, flipped class, blended, active learning

\section{INTRODUCTION}

Universities have various intentions for developing Massive Open Online Courses (MOOCs): these include experimenting with online learning as a tool for research into teaching and learning, to raise the profile of their institution, to improve the economics of delivering a course, improve learning outcomes in a class, or to raise the quality of educational materials. No matter what the rationale, the costs of developing a MOOC are high, certainly much higher than the cost of developing most face-to-face classes. [1,2].

MOOCs use several technology-enabled tools: quizzes, video lectures, community forums and peer-evaluations. In this paper we describe how quizzes and video lectures that were developed for a MOOC became the pre-class activities in a flipped environment. We go on to describe how those learning tools led into in-class activities. These activities are often the largest hurdle for the instructor flipping a course. We briefly mention how forums and peer-evaluations were used.

Before reporting on the adaptation of these tools we give a framework to conceptually understand flipped and blended classes in section 2, and how these environments relate to MOOCs and face-to-face classrooms. We also clarify a way of thinking about the flipped class. After discussing the flipped class used at McMaster University in section 3, we look at what was accomplished in section 4 , in light of Chickering and Gamson's work on principles for good undergraduate education [3].

The main conclusion we hope to impress is that an instructor of any current face-to-face course can blend and flip - fairly easily - certain aspects of their courses, using tools currently available.

\section{SOME TERMINOLOGY — IN CONTEXT}

As changes keep developing in the area of flipped environments, blended classes, face-to-face instruction and MOOCs, it might be helpful to describe a personal viewpoint of these concepts, which is also visually illustrated in Figure 1.

The horizontal dimension shown in Figure 1 is how the course instructor interacts with the students; there are two extremes. On the far left is the world of MOOCs, where students never interact in-person with the instructor, and on the other side is where students and instructors interact only in a face-to-face manner. Note that this axis is not intended as the extent with which interaction occurs. A face-to-face class can either be a heavily interactive active-learning environment, or it can be the stereotypical "sage-on-the-stage" space. In the latter case, the interaction is still only in-person, but not very interactive. In that regard, the extent of interaction might be a $3^{\text {rd }}$ axis, not shown here, and indeed, other axes are possible, as described later. 


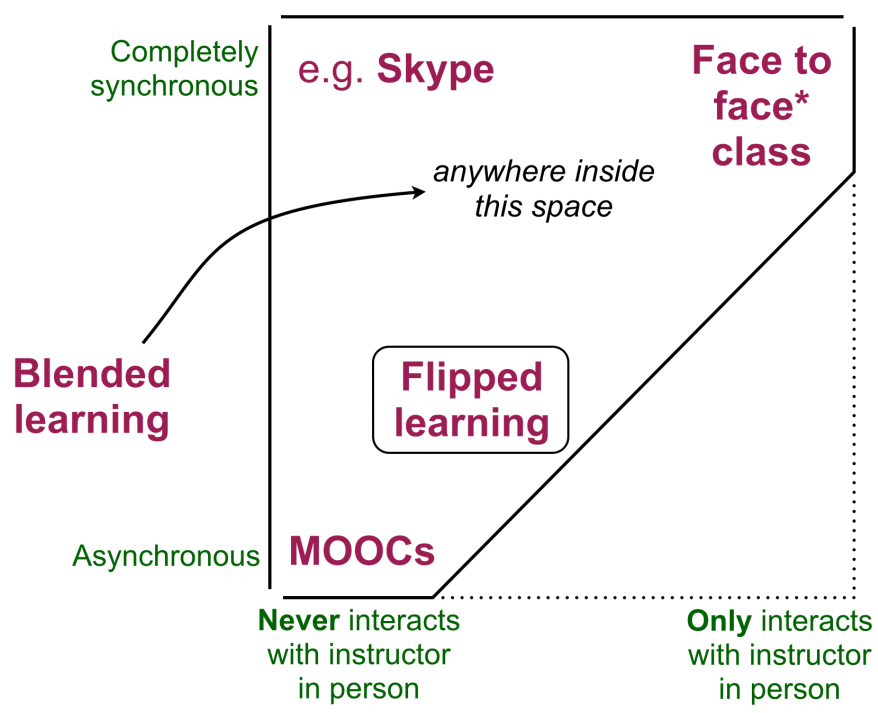

Figure 1: Conceptual viewpoint of courses from the perspective of two axes. Higher dimensions are possible.

The vertical axis in Figure 1 is the degree of synchronicity of interactions: either they are completely synchronous at the top of the axis, such as in a face-toface class, or the delays between interactions can be substantial: hours, weeks or even months are possible, or there might only be very weak expectation of interaction in a MOOC.

The bottom right corner is not reachable in a practical sense, and so this map is more triangular. In the top, left corner we could conceivably have a situation where the instructor delivers the class virtually, over a network connection, for example. Of interest is the diagonal region connecting MOOCs and face-to-face classes, and it is along here that this author visualizes the flipped class.

The flipped class, which is clarified next, can be understood as being closer to the MOOC-space, where interactions are mostly asynchronous and often over a computer network, rather than in-person. A blended class can be thought of somewhere else in the triangular continuum. In-fact, in this author's opinion, most classes in a typical campus are not at any extreme shown in this diagram. There are elements in regular campus courses which are more MOOC-like, such as asking students to read a course text and answer an electronic quiz prior to class. Most campus learning management systems now have on-line forums for students to ask questions and interact with the instructor or teaching assistants. On the other hand, elements in a course, such as having students work on and submit an assignment, are very asynchronous and often there is little expectation of student-instructor interaction for this activity.

With this notion of synchronicity and type of interaction as the two axes we can understand our current courses, and look at the individual elements within them, and where they lie. The sum of those individual elements within each course leads to a "blend", and the extent of that blend places the course on this map. The map can be made richer, if a bit more complex, by the addition of a $3^{\text {rd }}$ axis, such as the extent of interaction described earlier, or a $4^{\text {th }}$ axis which represents the class size, a $5^{\text {th }}$ axis of student's degree of autonomy in choosing the pace towards achieving their learning, a $6^{\text {th }}$ axis representing whether it is the instructor doing the teaching or one or more other virtual instructors, and so on. Section 4 of this paper hints at seven further dimensions that might be considered to enrich this map.

This map helps calibrate our understanding, to recognize that MOOCs are an extreme, and being an extreme, they have strong advantages and disadvantages, in the same way that a class delivered only in a face-toface format is an extreme. A blended (or flipped) learning environment can conceivably harness advantages from either extreme for the individual elements that make up the course. This notion can help instructors visualize and plan their courses, and chart the changes they make to their course from one occasion to the next.

When using the term "flip" in the context of a course, we should distinguish between both time and space (geography). Time can be flipped, where activities that ordinarily take place before or after class time are now done in the time scheduled by the university for studentinstructor interaction. When flipping time, we must also flip the geographical environment: the physical space ordinarily deemed appropriate for certain learning activities is inverted. These ideas are not the author's, but the composite thoughts of reading many blogs on this topic, particularly that of Talbert [4].

In a blended and flipped environment the notion of what ordinarily is done within the class space and class time is blurred. As Talbert describes in his articles [4], there is no before, during and after class hierarchy. Events that ordinarily take place in the class time and space, such as teaching a difficult or new concept, can take place at any moment when tools from the online and MOOC arenas are harnessed. Posing a difficult assignment can be done before class in a video, worked on during class with peers and the instructor, and continued after class with peers, or individually, for example.

Talbert also makes the distinction between flipping a class and the flipped learning environment [5]. Flipping a class is simply a logistical activity where time and location elements of the traditional face-to-face class are inverted. Flipped learning can be taken to imply a deeper, more fundamental change. It is a change that creates a different culture. A flipped learning culture is characterized by flexibility in learning modes, where different modes work more successfully for different students [5]. A culture of inquiry is created in this environment, and a sense of greater self-autonomy is 
created. The instructor's role is also modified: they become more of a collaborator with other (potentially virtual) instructors, and these collaborators could teach technical content, or assist with the course design. In the same way a flipped class encourages group activity and peer learning, the instructor is to be held to the same standard: engaging and interacting with other instructors and educational professionals on their courses.

\section{APPLYING MOOC TOOLS IN A BLENDED CLASS AT McMASTER UNIVERSITY}

Three distinct tools adapted from online courses are readily available to use in the blended or flipped class: pre-class activities (quizzes and videos typically), forums, and peer-evaluations. We describe in depth the first one, and following that, how the in-class activities tie to the pre-class activities.

The main reasons for using the MOOC material in this McMaster University course were two-fold: firstly, finalyear students are about to embark on their careers, and an important aspect of engineering is to maintain relevant skills with life-long learning. Using online courses for learning is an unfamiliar experience to current students, however one that is easily available in their future. This course was a single opportunity to demonstrate this before their graduation. Secondly, the tremendous capital costs of developing the MOOC $(\$ 45,000$ of direct costs and over 900 hours of time to create the videos and some of the learning materials), should be amortized, where possible.

As background, the course is a final year course, titled Statistics for Engineering. It has been offered for about 30 years, and the current author has taught it primarily faceto-face from 2010 to 2014 , on 5 occasions. The course covers 5 main modules: (1) data visualization, (2) introductory statistics, probability and confidence intervals, (3) linear regression, (4) design of experiments, and (5) process monitoring. Material from one section of the course, on designed experiments, was offered on Coursera for the first time as a MOOC in 2014 [6], and is being offered on an ongoing basis.

The class in 2015 (99 students) used the MOOC material in a flipped manner, as described next. At the end of the course a survey on various aspects of the course was run. The remainder of this paper is based on these qualitative responses, and quotes from these survey responses are provided in italics. Student responses to that survey, as well as the official McMaster University course evaluation are available [7] for those seeking a more detailed insight, beyond the summary provided below.

\subsection{Pre-class activities}

Students in a flipped environment are expected to complete a certain amount of work prior to class time.
These activities can be as varied as reading through one or more assigned papers or book chapters, watching videos, answering quizzes and questionnaires (electronically or on paper) and pre-class group work, or a combination of these.

In this course the activities were to watch several videos and to supplement that with reading sections of the free course textbook [8]. The students were asked to individually answer a short electronic quiz. This pre-class quiz had all the functionality offered by typical MOOCs, since Coursera allowed us to use their platform to run a private course, open only to students enrolled in the McMaster course. This functionality includes multiplechoice questions, fill-in-the blanks (numeric and text) and checkbox answers. Other question types are possible, but were not used.

The quiz was between 5 and 8 questions, and tested mainly simple factual concepts and straightforward calculations. Quiz answers were released 5 minutes prior to the scheduled class, and most questions had full solution descriptions for both correct and incorrect options. The quizzes preceded every class, and there were 22 such quizzes by the end of the course. Quizzes had no time-pressure aspect, so students could take as long as they wanted to answer the questions.

The intention is that students will watch the videos and/or read the textbook, then attempt the quiz. Some students commented they would work on both in parallel. Much adjustment was necessary: a student indicated that: "With an online course most people didn't take notes the same way, or at all... I am not sure if there are tips for taking notes with online courses, but providing a reference may be useful because I found that it was harder to make effective notes". Another student commented: "I personally found the course video approach to be significantly more challenging to gain the same level of understanding of the course material from. This is due to the necessity of developing a different method of notetaking, learning and application than I have been accustomed to in all prior courses. That being said, I recognize that, particularly in professional skill development in the future, this type of learning will without doubt be important: therefore exposure to this type of course at least once in undergrad is a valuable experience". Various other strategies were described in the full survey data [7].

The intention behind the quizzes was multifaceted. Firstly, frequent tests, spaced across time leverages two well-studied cognitive effects: the testing effect and the spacing effect [9]. Unfortunately quiz feedback was not provided early enough to also invoke the feedback effect [10]. Ideally, students would have several hours prior to class to examine the quiz feedback automatically provided after the test. This will be a change to make for future classes. 
Other enhancements to improve the effect of pre-class activities were recommended by students and subsequently uncovered in the literature. In rerunning this course we would include prior concepts in the pre-class tests. One suggestion from a colleague [11], is to have $40 \%$ of the questions from concepts from prior modules, $40 \%$ of questions on the current topic, and $20 \%$ of questions posed as challenges, extending the student beyond the topic assigned for that day. It was humbling to read several similar suggestions in the student reviews received after the course.

In fact, Schneider et al. [12] showed that students which are challenged prior to class time with open-ended exploration questions outperformed students that used only traditional textbook materials. These questions are certainly harder to automate for grading purposes, but not impossible. They might be posed as a sequence of steps for the students to follow, for example: "Enter these lines of code in the software [give code which generates a plot]; which of these options best describes the interpretation of the plot [give several multiple choice options]". In non-software courses, these might be replaced by steps in an exploratory calculation, or a description of a thought experiment.

Other improvements, based on student feedback, are to ensure that all concepts are covered in the quizzes, and post the quizzes at least 24 hours, ideally 48 hours, prior to the class. This creates a sense of control over time, which is so critical to student success [13]. Managing time became really difficult during the middle and end of term when other course tests and projects were also being worked on. Having the quizzes posted earlier would have alleviated the stress we induced by posting the quizzes less than 1 day prior to class. For example, a student admitted he posted random answers to the quiz, a strategy which works for the student, but defeats the intention of the quizzes.

Students greatly preferred when they had 2 attempts at the quiz, even though the answers are not shown between attempts; answers are only revealed for everyone at the quiz deadline. Several students did complain about the quiz frequency: "At the time, it seemed excessive and sometimes annoying to have constant quizzes, sometimes being released last minute. At the end of the term it really paid off though and I found that being forced to keep up with the course tremendously decreased the amount of studying I needed to do for the exam."

It is critical to realize that the intention of the pre-class quizzes is not a punitive enforcement of doing the required prior work. This leads to the second facet related to using electronic quizzes is to prime students, and get them ready to come to class with a frame of inquiry and critical questions. As a student commented: "my thinking was already geared towards the specific task". We are not naive however, since grade weights are also an extrinsic motivator. Providing a significant weight to the overall grade for pre-class activities is required to encourage motivation. Students are strategic about their time spent. Indeed, time-management is a key outcome in assessing Engineering attributes in Canada, and it should be no surprise that students use grade weights as a signal from the instructor on where their time should be allocated.

A third and final facet for using pre-class quizzes was to find the problematic concepts that would help shape the class time (see the next subsection). These troublesome concepts can be readily identified once about 30 to 40 students had answered the quiz; results did not change much after this number of quiz responses. This gave the instructor about 3 hours prior to class to enhance the planned in-class activity, described next.

\subsection{In-class activities}

3.2.1 Description of in-class time. The instructor's vision or mental template for time spent in class for the course was to have a quick recap of important concepts at the start of the class for about 5 minutes. Students would then work on a worksheet, in groups of 2 or 3 , interjected with short comments announced to keep students on pace, and bring important concepts to their attention. This was modified, since students would arrive late and disrupt the recap. The recap ended up being omitted, and students started right away on the worksheet. In hindsight this was short sighted; as commented on in subsection 3.2.3.

The worksheet was the graded deliverable: with questions on both sides of the paper, and space to fill in answers. The students were expected to complete it in the class time, in their groups. The groups were self-selected and remained the same throughout the semester. Gauging an appropriate amount of work was something quickly calibrated after a few classes which were either too short or too long. A long class was rescued by indicating that only the first few questions would be graded, leaving the later questions as challenges, or, as was sometimes done, repeating them as assignment questions. That way students that did attempt them felt they had not wasted time in class.

Students completed the worksheet with their answers: this included fill-in-the-blanks, drawing sketches (e.g. histograms), full sentence interpretations of software output, multiple choice answers (with justifications), annotating plots, drawing graphs where the gridlines were already given, filling in tables of results and then interpreting them. Some classes also had gamified elements, where the groups competed against a serverbased simulation, and a projected leaderboard and prize money added some incentive to compete. There are many options for class activities, and examples of the class worksheets are available on the website that accompanies this work [7]. 
Once finished, the groups could leave after they scanned their sheet through a compact, double-sided scanner (ScanSnap S1500M). This meant that students retained their work to review at home, they could complete questions after class, and could instantly compare their understanding with the solutions that were posted within 12 hours. This last aspect leverages the feedback effect again [10] in an advantageous way. The electronic scan, the PDF, was graded by the teaching assistants on a scale of 0 (no attendance), 1 (very poorly completed), 2 (some or most concepts correct), 3 (nearly all concepts well understood). There were 19 of these graded activities, and TAs took about 2 hours to grade and enter the grades for the 40 submissions. From a logistical point of view, this approach also meant that no papers had to be physically collected and returned (with an associated longer feedback cycle). A 5 point scale will be considered in the future, based on student feedback.

Communication was key to make class-time work successfully. Expectations were clearly stated in the course outline. Students knew that something would be due at the end of each class, and that it would count for grades. To emphasize this, the very first class used the format discussed above, and the activity was to answer various questions based on the course outline.

\subsubsection{The changed role of the instructor. The role} envisioned by the instructor will change in a flipped class. Questions on every imaginable aspect were asked by students: from simple concept clarifications, to software troubleshooting, to challenging and though-provoking questions. It was really exciting to see so much activity in the class throughout the 50 scheduled minutes for it. Common questions that were noticed while the students worked on the worksheet were addressed. The class would be paused, the concerns addressed to the whole class and then the class could continue on. It was also a good opportunity to refocus the student's attention to the work, and to indicate the instructor's expectation on how far along the worksheet they should be.

Notice that this role is very different from the stereotypical sage-on-the-stage or the guide-on-the-side model that is often mentioned. It is neither of these. The role is a mixture of coordinator, mentor, time-manager and requires responsive answers to fairly tough questions occasionally. This was also noted by Bruff et al. [14]. This might be unexpected and uncomfortable for many instructors, but the advantage is an opportunity to make real connections with students. For example, it led to this instructor noticing prolonged absences from class in some student cases, as well as fruitful, on-going discussions with students from one class to the next. This change in instructor self-perception is no different to teaching an online course where the instructor has to re-vision their role with more emphasis on being a curator or filter of a variety of potential electronic resources, including selfcreated resources.
3.2.3 Improvements to make in the future. Some changes to make were reflected on in the prior subsection, but the most common request was related to in-class time: fewer activities and more teaching by the instructor. This actually became apparent fairly early on in the course, when some students indicated that they lost the connection with the instructor when videos did not have the instructor's face in them at the start.

Requests for more teaching is a very common issue in flipped classes; sentiments such as "the instructor should actually 'teach", were not entirely unexpected, based on comments and insight reported by Talbert [15]. He comments in that article that teaching is actually more refined in a flipped class, since all the delays, hesitations, repeats, and interruptions are edited out. In fact, this was the basis for eliminating one of the scheduled 50 minute classes at McMaster, leaving two classes for the flipped, activity-based exercises. The intention was that the cancelled class time could be used to time-shift, freeing up time for students to watch the carefully edited videos, which always totally less than 50 minutes.

In hindsight, it seems that students really wanted that scheduled extra time with the instructor too. Many suggestions by students were received on what to do with that extra time, most of them related to covering difficult concepts in class, teaching the odd lecture, and reviewing pre-class quiz problems. All of these are great suggestions and will be used going forward.

The student comments point to the desire for a more blended environment, rather than a purely flipped environment (cross-reference figure 1). In hindsight, using a mostly flipped class, less than $10 \%$ lecturing, in 2015 was too extreme. This is in contrast to the five prior instances of teaching the course face-to-face, and the MOOC experience in 2014. It provides a greater sense of calibration now that each of these reference points have been explored. Future classes will be more balanced and blended: about $35 \%$ of teaching time is intended.

Other changes that will be made are to consider an advanced or "challenge" worksheet option, especially during the modules at the start of the course which have more of a review orientation of prerequisite materials. These challenge worksheets are to target the students that finish well before the end of the class, and aims to exploit the 7th principle outlined by Chickering and Gamson [3] (see section 4).

3.2.4 The irony of using online tools for teaching. Even though class worksheets were roughly planned in advance, they had to be tweaked and enhanced to focus on the problematic concepts identified by student questions posted in the forums and based on pre-class quiz results. It can be rightly argued that this insight should also go towards improving the pre-class readings and videos. 
It is an irony that online learning tools have such a long and costly feedback cycle to make improvements. Online tools have the connotation of being fast and responsive. However, the cost and time to remake a video is substantial, given the expertise and number of people involved. Getting it right the first time is critical.

Once again, this points to an advantage of the blended class. Verbal cues, non-verbal body language and facial expressions can be used by the instructor to gauge confusion and an improved, alternative explanation of the concept offered in the moment; not so in an electronic environment. MOOCs are now able to report "hotspots" where videos are rewatched, which is a distinct advantage over the face-to-face class where the instructor might not be able to always read the non-verbal feedback. However, the cost of improving the video still remains a roadblock, and those improvements generally only benefit the next cohort.

3.2.5 Student perceptions of in-class time. Students did not mind the challenge of the new learning style, but it appears from the feedback, that a less extreme change might have been more successful, while still giving them the experience of a flipped environment. This is no different to the scaffolding principle which is known to be important for successful learning: provide supports early on, then gradually move them away [16, p 132].

Some quotes from students were: "I LOVED the tutorial style classes over traditional lectures. It really gave me a reason to come to class and I feel like I knew the material much better." and "The in class activities seemed intimidating at first but ended up being really helpful. They ensured that we had exposure to questions based on each week's material. As well, they helped me to find which concepts I was struggling with so that I could go back and watch the course videos for those topics", which was an interesting perspective not considered. Other students commented that this format kept them up to date with the course, more engaged with the material, and that they barely had to study for the final exam.

Some of the negative sentiments were: "Halfway through the semester when we were really busy with other classes, we couldn't watch videos and thus couldn't complete worksheets. We would fall behind and it would be quite stressful. I think a good solution is to have lectures a few classes instead of having videos on those days". Further justification for some targeted lecturing based on challenging worked examples: "Having group activities in class does not expose the students more to the professors experience and knowledge. Using the only two hours they have with the lecturer on doing exercises that could easily be done at home costs them a lot. I strongly believe that the class time should be discussion/lecture based.", and "I would prefer if you taught the tricky math stuff in class." Finally: "I wished somedays were lecture and no class activities. I was getting exhausted doing the class activities. Lectures would have helped me understand the material better. I believe there should be a balance between lecture and class activities in the future."

\subsection{Forums and Peer-evaluation}

Forums for peer interaction, and peer-evaluation of work that cannot be readily auto-graded are comment features in MOOCs. These two aspects were heavily adapted for the flipped classroom in the McMaster course and are only briefly described here, possibly being expanded on later [7].

Much literature exists on the use of discussion forums [17 provides much insight] and peer-evaluation in class. The results from this course do not depart much from those findings: students were somewhat reluctant to participate in the forums, but greatly appreciated the ability to post anonymously and still receive credit for their posts. Students in the summer MOOC posted on average 25 posts per participant completing the MOOC, while the ratio in the blended class was approximately 5 posts per student, another dimension that might be added to figure 1 .

The student-assigned grades for peer-evaluations correlated with the instructor's grades, in general, though were slightly inflated. The findings that a good, clear rubric is required, and that examples of graded work by the instructor should be made available were echoed by the experience in this course.

Instructors wishing to implement those two tools would do well to investigate the use of Piazza.com for forums, and PeerScholar.com for peer-evaluation. This will allow the benefits of these two tools to be had, without requiring access to a MOOC platform.

\section{REVIEW OF THE MOOC ADAPTATION IN THE CONTEXT OF CHICKERING AND GAMSON'S WORK}

Chickering and Gamson's frequently cited work on good practices for higher education [3] can be used to assess whether the adaptation of the MOOC materials was successful. Applying their seven principles to this course, and indeed any blended/flipped course is possible:

1. Contact between students and faculty is a central feature of the flipped learning environment. Compared to the five prior face-to-face classes taught by this instructor, the flipped class in 2015 lead to a stronger appreciation of the student's struggles with the material. Contact with students occurred both in class time and virtually, through the course forums.

2. Peer-learning was required during in-class activities, the course assignments and the course 
project. Groups of 2 or 3 students were used. Groups were encouraged to collaborate between each other as well towards the goal of understanding the material. Much of the student comments indicated that learning was solidified in peer activities during class time.

3. All the in-class activities were examples of active-learning. This also occurs outside of class on the course forums. For example, students had to comment on bad data visualization plots using their own prior lab reports. Other intentional forum questions were posed to stimulate out-of-class activity. They had to apply their knowledge to an actual designed experiment, and provide photographic or video proof of their work, to demonstrate their knowledge.

4. Prompt feedback was provided by making solutions of in-class activities available in less than a day. Solutions were also provided in the electronic quizzes, both for correct and incorrect options. However, it was left up to students to review this feedback themselves, since it was felt appropriate for this final-year course.

5. Time on task was required, even enforced, with the 50 minute worksheets completed in class time. Admittedly students felt pressured occasionally, but it was interesting to see students quickly starting the work, even arriving early to get a head start. There was much less non-course-related discussion in this class than other prior classes.

6. High expectations were clearly communicated right from the first class. The end goals were shown: students would learn a new statistical computer language that is widely used in industry, and they would develop the ability to design and run experiments - a very valuable skill demonstrated by showing job postings, and having guest lectures.

7. Diverse talents and ways of learning were encouraged in this flipped and blended class. Students did not have to only watch videos. They could seek out the materials on other websites, use the freely available course textbook [8] or other textbooks. The printed materials were available at the start of the course, so students could accelerate when they had free time. In future offerings of the course the video material will be made fully available at the start, to encourage this behaviour.

It is fascinating to see how the use of MOOC tools in a blended class so prominently activated these 7 practices of good eduction. They do so with much greater ease than the face-to-face synchronous class environment, where all students are held to the same pace.

\section{Acknowledgements}

The author wishes to acknowledge the incredible contributions of Devon Mordell, currently Instructional
Designer in the McMaster Institute for Innovation and Excellence in Teaching and Learning (MIIETL). Her insight into online learning and assistance with focussing the learning materials made a tremendous difference to the MOOC and the use of the MOOC materials in class. McMaster University also graciously thanks Coursera for allowing us to use their MOOC platform to deliver an oncampus class in a flipped and blended manner.

\section{References}

[1] Fiona M. Hollands and Devayani Tirthali, MOOCs: Expectations and Reality, Full Report, May 2014, Center for Benefit-Cost Studies of Education Teachers College, Columbia University, http://files.eric.ed.gov/fulltext/ ED547237.pdf

[2] Fiona M. Hollands and Devayani Tirthali, Why Do Institutions Offer MOOCs? 2014, http://cbcse.org/ publications/

[3] Arthur W. Chickering and Zelda F. Gamson, "Seven principles for good practice in undergraduate education" American Association of Higher Education Bulletin volume 39, no.7, pp.3-7, 1987.

[4] Robert Talbert, http://chronicle.com/blognetwork/ castingoutnines/author/robert/

[5] Robert Talbert, Toward a common definition of "flipped learning", 01 April 2014, http://chronicle.com/ blognetwork/castingoutnines/2014/04/01/toward-acommon-definition-of-flipped-learning/

[6] Kevin G. Dunn, Experimentation for Improvement, Massive Open Online Course on Cousera, (2014).

[7] Kevin G. Dunn, Materials supporting this work, http://yint.org/flipped-mooc

[8] Kevin G. Dunn "Process Improvement using Data", 2010-2015, http://learnche.mcmaster.ca/pid

[9] Nicholas J. Cepeda Edward Vul, Doug Rohrer, John T. Wixted and Harold Pashler, "Spacing effects in learning: a temporal ridgeline of optimal retention", Psychological Science, vol. 19, no. 11, 2008. DOI: 10.1111/j. 1467-9280.2008.02209.x

[10] Pooja K. Agarwal, Jeffrey D. Karpicke, Sean H. K. Kang, Henry L. Roediger III and Kathleen B. McDermott (2008), Examining the testing effect with open-and closed-book tests. Applied Cognitive Psychology, vol. 22, pp. 861-876. DOI: 10.1002/acp.1391

[11] David Brock, Department of Chemistry and Chemical Biology, McMaster University, comments made 
at Learning Technologies Symposium, McMaster University, 20 May 2015.

[12] B. Schneider, J. Wallace, P. Blikstein, R. Pea, "Preparing for future learning with a tangible user interface: the case of neuroscience", IEEE Transactions on Learning Technologies, vol.6, no. 2, pp. 117-129, April-June 2013, DOI:10.1109/TLT.2013.15

[13] Jennifer Case and Richard Gunstone, "Going deeper than deep and surface approaches: A study of students" perceptions of time", Teaching in Higher Education, vol. 8, no. 1, 2003 DOI: 10.1080/1356251032000052320

[14] Derek O. Bruff, Douglas H. Fisher, Kathryn E. McEwen, and Blaine E. Smith, "Wrapping a MOOC: Student Perceptions of an Experiment in Blended Learning", MERLOT Journal of Online Learning and
Teaching, vol. 9, no. 2, June 2013, http://jolt.merlot.org/ vol9no2/bruff 0613.htm

[15] Robert Talbert http://chronicle.com/blognetwork/ castingoutnines/2014/05/05/flipped-learning-skepticismdo-students-want-to-have-lectures/

[16] Susan A. Ambrose, Michael W. Bridges, Michele DiPietro, Marsha C. Lovett, Marie K. Norman, "How Learning Works", Jossey-Bass, 2010

[17] Michael Caulfield, Amy Collier and Sherif Halawa, "Rethinking online community in MOOCs used for blended learning", 2013, http://www.educause.edu/ero/ article/rethinking-online-community-moocs-usedblended-learning 